\title{
Coupling of clouds and tropospheric relative humidity in the tropical Western Atlantic: insights from multi-satellite observations
}

\author{
Hélène Brogniez ${ }^{1}$, Pierre-Emmanuel Kirstetter ${ }^{2}$ \\ ${ }^{1}$ LATMOS/IPSL, UVSQ Université Paris-Saclay, Sorbonne Université, CNRS, Guyancourt, France \\ ${ }^{2}$ University of Oklahoma / NOAA National Severe Storm Laboratory, Norman, USA
}

\section{Key Points:}

- The daytime drying of the mid-troposphere is associated with the large-scale subsidence and presumably with the diurnal pulses of ITCZ.

- The diurnal cycle of upper-level cloudiness is essential for tropospheric moistening by inducing local lifting.

- The upper level moisture feeds upper-level clouds and modulates their diurnal cycle.

Corresponding author: H. Brogniez, helene.brogniez@latmos.ipsl.fr 


\section{Abstract}

We investigated the interactions between clouds and moisture at the diurnal scale in the Western Atlantic trade winds region. Profiles of tropospheric relative humidity from the SAPHIR/Megha-Tropiques sounder are combined with cloud categories obtained from geostationary satellites. In Winter, the mid-troposphere undergoes strong daytime drying due to air masses coming from the colder upper troposphere. The moistening near the surface triggered by solar radiation precludes the development of low-level clouds. At night rising moist air in the upper troposphere triggers the formation of high-altitude clouds and favors their presence. In Summer, daytime high-altitude clouds shield the solar forcing on the atmosphere and reduce drying from large-scale subsidence. After sunset, the development of upper tropospheric opaque clouds constitutes a local source of moisture. We argue that modulations of the diurnal cycle of clouds and relative humidity by season may be related to diurnal pulses of the ITCZ.

\section{Plain Language Summary}

The heat engine of the climate is the atmospheric water cycle. Understanding the relationships between clouds and the atmospheric relative humidity is crucial to improve our understanding of climate variability. Here we focus on the diurnal fluctuations of vertical profiles of tropospheric relative humidity and collocated clouds in the tropical Western Atlantic trade winds region. Profiles of water vapor and distribution of clouds, classified by altitudes, are obtained from space-borne instruments, and the other environmental characteristics such as sea surface and air temperatures are extracted from a weather model. Their joint diurnal variations are examined. Winter and Summer seasons are compared. The diurnal water vapor cycle of water vapor evolves from the bottom to the top of the atmosphere and is strongly associated with cloud types, with a seasonal modulation. During daytime a strong drying is associated with the downward dry air masses moving downward. The diurnal cycle of upper-level cloudiness plays a critical role in inhibiting daytime drying by shielding the mid-troposphere from this downward transport. The upper-level moisture feeds upper-level clouds and modulates their diurnal lifetime.

\section{Introduction}

There is no doubt that we need to improve our understanding of how clouds and cloudrelated feedbacks impact on climate (Stephens et al., 2002; Bony et al., 2015). Critical 
processes involving clouds and water vapor, such as detrainment and evaporation, typically occur at time scales of less than 6 hours. This calls for sub-daily analyses of observations. Regional variations in the diurnal cycle of clouds are caused by several parameters such as orography, land/sea circulation, air-sea fluxes and sea surface temperature (SST), their effect differing with the dominant cloud type (Yang \& Slingo, 2001; Eastman \& Warren, 2014; Noel et al., 2018). The role of the free tropospheric water vapor in the evolution of clouds at the diurnal scale has not been extensively studied due to lack of observations. An improved understanding of how different cloud types and their diurnal cycles interact with the atmospheric water vapor is much needed in order to make the connections between the solar forcing, the surface and the atmospheric water cycle (cloud, vapor and rain).

For example, observations of rainfall rates associated with deep convection in the Indian Ocean warm pool region have revealed a predawn rainfall peak (Mapes \& Houze, 1993; Sakaeda et al., 2018) triggered by solar absorption (Sakazaki et al., 2017) and invigorated by the oceanic warm layer in some regions (Bellenger et al., 2010). Ruppert and Johnson (2015) have highlighted the existence of a deepening of daytime convective clouds along with a parallel increase in moisture in the lower troposphere. In this region of the upward branch of the ITCZ characterized by active convection, these diurnal pulses are favored by a combination of increasing SST in the daytime and a reduced large-scale subsidence. These pulses are thought to further affect remote shallow convective areas through a strong feedback on daily precipitation and convective heating (Ruppert, 2016; Ciesielski et al., 2018).

The impact of clouds on solar radiation and related heating has also been addressed in numerous works. The direct absorption of shortwave radiation by optically opaque and elevated clouds (anvil-type clouds) is thought to cause a strong cloud-top heating (Hartmann et al., 1984; Ackerman et al., 1988; Mather et al., 2007; Powell et al., 2012) that increases buoyancy below, and a lifting towards the upper-levels, thereby causing a daytime peak in upper-level cloudiness to prevail (Ruppert \& Klocke, 2019). Atmospheric tides, driven by solar heating and ozone absorption, have also an effect in the diurnal convection cycle and subsequent precipitation (Woolnough et al., 2004).

Studies focusing on oceanic shallow convective clouds, such as Stratocumulus and $\mathrm{Cu}-$ mulus, have shown that their diurnal cycle is linked to lower-tropospheric stability with a large-scale meteorological influence (Klein \& Hartmann, 1993; Wood, 2012). The maximum 
of occurrence of these low-level clouds has been observed in the early morning hours before sunrise and their diurnal cycle depend strongly on the region (Klein et al., 1995; Rozendaal et al., 1995; Eastman \& Warren, 2014). The recent work of Vial et al. (2019) highlighted the challenge for high resolution models to represent the daily cycle of such shallow clouds. For example Chung et al. (2007) examined convectively active parts of Africa and the Atlantic ocean with the METEOSAT geostationnary satellite. They revealed a peak on the Upper Tropospheric Humidity (UTH) at 3:00LT with a clear contrast between land and ocean, which remains a challenge to represent in several reanalyzes, thereby highlighting missing processes related to moisture (Chung et al., 2013).

To our knowledge, few studies have analyzed the diurnal cycle of atmospheric moisture. In addition, most studies have focused on UTH (a vertically-weighted integral of relative humidity zooming in the upper troposphere) rather than considering the vertical distribution of humidity. Moradi et al. (2016) showed that peak times for tropospheric relative humidity varied throughout the tropical belt using the Megha-Tropiques satellite. Chepfer et al. (2019) used the CATS spaceborne lidar to related this diurnal variability to the vertical properties of clouds.

In this study we analyze the relationships between clouds and atmospheric relative humidity $(\mathrm{RH})$ and their joint diurnal variations by fully exploiting an ensemble of observation data from different space-borne instruments. We address the following question:

How are RH and clouds linked at the sub-daily scale? Specifically is there a signature in $\mathrm{RH}$ before or after the cloud growth at the sub-daily scale ?

We focus on the tropical Western Atlantic region, $\left(70^{\circ} \mathrm{W}-30^{\circ} \mathrm{W}\right.$ in latitude and $10^{\circ} \mathrm{N}$ $30^{\circ} \mathrm{N}$ in longitude) subjected to the large-scale forcing of the downward branch of the Hadley cells. This region is mostly characterized by shallow convection and most clouds are Stratocumulus and Cumulus. Vial et al. (2019) discussed the diurnal variability of cloud-base in this region through the prism of ground-based measurements and regional models. We aim to expand previous studies that investigated the diurnal variations of the ITCZ (Ruppert \& Johnson, 2015; Ciesielski et al., 2018; Sakaeda et al., 2018) at its edges and offer new insights on the diurnal cycle of the subsiding branch of the overturning circulation. 


\section{Data and Methods}

\subsection{Datasets}

Satellite estimates of cloud types and RH profiles are combined with other environmental parameters from the European Center for Medium-range Weather Forecast (ECMWF) ERA-5 reanalysis (Hoffmann et al., 2019).

The RH profiles are derived from the SAPHIR sounder on Megha-Tropiques. Since October 2011, this satellite provides 3 to 5 observations daily at any given point of the tropics. Its equatorial crossing time shifts backward by 100min due to the precession cycle of the platform (Roca et al., 2015). SAPHIR provides humidity profiles throughout the troposphere by sampling the atmospheric moisture in the $183.31 \mathrm{GHz}$ line with six channels. The $1700 \mathrm{~km}$-swath of SAPHIR covers the $\pm 30^{\circ}$ equatorial belt. Its nominal observations are performed at a horizontal resolution of 10km at nadir. Here we use the operational Level 2 RH profiles described in Sivira et al. (2015) and Brogniez et al. (2016). RH is preferred over absolute humidity to avoid dependency to temperature profiles.

Cloud types are taken from the Numerical Weather Prediction - Satellite Application Facility (NWP-SAF) algorithm developed for geostationary satellites (Derrien \& Le Gléau, 2005; Sèze et al., 2015). A finer spatial scale is available for these cloud types than for RH profiles, which provides up to 20 geostationary pixels within each of the larger SAPHIR footprints. We consider five cloud types: "Very Low" with cloud top pressure $\mathrm{P}_{t o p}>$ 800hPa, "Low" with $\mathrm{P}_{t o p} \in[650 \mathrm{hPa} ; 800 \mathrm{hPa}]$, "Medium" with $\mathrm{P}_{\text {top }} \in[450 \mathrm{hPa} ; 650 \mathrm{hPa}]$, "High Opaque" and "High Semi-transparent" with $\mathrm{P}_{\text {top }}<450 \mathrm{hPa}$. Among the cloud types in the trade winds, as defined by (Riehl, 1954), the Very Low category can be associated with shallow convective clouds with tops that do not exceed 4km, such as Cumulus Humilis and Chimney clouds. High Opaque and High Semi-transparent clouds are distinguished from each other by their concentration of water (ice/liquid) and their optical thickness.

The conditional evolution of RH for a given cloud type is nailed down by selecting SAPHIR footprints dominated by a given cloud type : if more than $90 \%$ of a SAPHIR footprint is filled with geostationary pixels of the same type, then the corresponding $\mathrm{RH}$ profile is attributed in its entirety to this particular type. This cautious selection retains only $\sim 30 \%$ of the total observations. It allows to extract clear co-variations between the clouds and the corresponding RH profiles. 
Environmental conditions are described with ECMWF ERA-5 outputs at the $0.75^{\circ}$ latitude-longitude resolution grid:

1. skin temperature (SkT), used to relate to the solar heating;

2. air temperatures at $500 \mathrm{hPa}\left(\mathrm{T}_{500}\right)$ and $200 \mathrm{hPa}\left(\mathrm{T}_{200}\right)$, to deconstruct the moisture and temperature signatures within the variability of $\mathrm{RH}$;

3. lower tropospheric stability (LTS) that provides a measure of the inversion strength between the surface $\left(\theta_{0}\right)$ and above the atmospheric boundary layer $(\mathrm{ABL})$ at $700 \mathrm{hPa}$ $\left(\theta_{700}\right)$ (Klein \& Hartmann, 1993);

4. $10-\mathrm{m}$ wind divergence $\left(\nabla \vec{U}_{10 \mathrm{~m}}\right)$ and $500 \mathrm{hPa}$-vertical atmospheric velocity $\left(\omega_{500}\right)$ as indicative of the dynamical flows.

All these parameters are considered at the hourly time scale, except $\omega_{500}$ that is used at the monthly time scale to define climatologically stable conditions. All outputs are translated into the local time of observation (LT).

\subsection{Method: composite diurnal cycle}

All instantaneous observations from the Western Atlantic sub-region taken during the periods January-February-March (JFM) and July-August-September (JAS) 2012-2017 are gathered to create a composite diurnal cycle for all variables.

In order to link with large-scale dynamics, the data is categorized into ascending $\left(\omega_{500}<0\right)$

and subsiding $\left(\omega_{500}>0\right)$ categories. Relative anomalies of each variable with respect to their daily averages are computed as follows:

$$
Y^{\prime}(t)=100 \times \frac{Y(t)-\bar{Y}}{\bar{Y}}
$$

where $Y(t)$ is either the number of situations of a given cloud type or the $\mathrm{RH}$ value at a given pressure level at time $t$ (hours), and $\bar{Y}$ is the corresponding daily mean.

Harmonic functions are fitted on the composite hourly time series using a least-squared error method, with a diurnal harmonic (24h cycle) and a semidiurnal harmonic (12h cycle; see example on Fig. 3). From these fits, lagged-correlations are computed between anomalies of RH with respect to time $t$ and $X$ (cloud prevalence or environmental parameters) with respect to time $t+i$. They are noted $R(i)$ for a time lag $i$, with $\sigma_{R H}$ and $\sigma_{X}$ the variances of $R H$ and $X$ :

$$
R(i)=\frac{E\left[\left(X_{t}-\bar{X}\right)\left(R H_{t+i}-\overline{R H}\right)\right]}{\sigma_{X} \sigma_{R H}}
$$


The correlation significance is tested with a Student t-test (95\% confidence interval).

\section{Results}

\subsection{Regional temporal variability}

Figure 1 displays the seasonal differences in large-scale circulation in the tropical Western Atlantic area with a climatology of $\omega_{500}$ (Fig.1 a-b) and the diurnal fluctuations of SkT, $\nabla U_{10 m}$ and LTS (Fig.1 c-d). During JFM, this region is subjected to strong subsidence aloft (Fig.1 a). During JAS, the region is on the edge of the ITCZ and is generally characterized by weaker vertical motions (Fig.1 (b)). In terms of cloudiness, the two seasons are populated by different cloud types: during the JFM period, low-altitude clouds associated with the trade winds are dominant, while the JAS period is characterized by both high and low-altitude clouds associated with the ITCZ ((Konsta et al., 2012); see also Fig. 2). We focus on the large-scale subsiding category $\left(\omega_{500}>0\right)$ to minimize the sampling of deep convective systems by the SAPHIR microwave sounder (Burns et al., 1997; Brogniez et al., 2013).

The environmental conditions displayed on Figures 1c-d provide insight into the processes governing the formation of clouds. Surface warming by solar heating reaches a maximum at 12:00 LT, and is associated with a known weak cycle in $\nabla \vec{U}_{10 m}$ (Nitta \& Esbensen, 1974), that is almost inexistent during JAS, and with a steadily increasing LTS. The diurnal variations in LTS indicate lower instability in the morning hours (minimum of LTS at 4:00 LT) at the same time as the peak of cloud occurrences (Fig. 2 a-e). In both seasons, increased stability is observed as the day progresses until a peak is reached around 18:00-20:00 LT which inhibits vertical cloud extension. In JFM, a second peak of LTS is observed at 9:00 LT coinciding with the start of solar heating, and, to a lesser extent, with the daily maximum of wind convergence. Vertical heating of the atmosphere shifts progressively over time from the bottom ( $\mathrm{SkT}$, maximum at 12:00 $\mathrm{LT})$ to the middle $\left(T_{500}\right.$, maximum at 16:00 LT) and then to the top $\left(T_{200}\right.$, maximum at 20:00 LT, with a second maximum near 8:00-10:00 $\mathrm{LT})$.

Figure 2 shows the hourly evolution of the prevalence of the five cloud types within the Western Atlantic area along with the daily fluctuations in the average $\mathrm{RH}$ profile for JFM (a-d) and JAS (e-h). In order to highlight the amplitude of the diurnal cycle, relative 
(a) ERA-Interim JFM 2012-2017

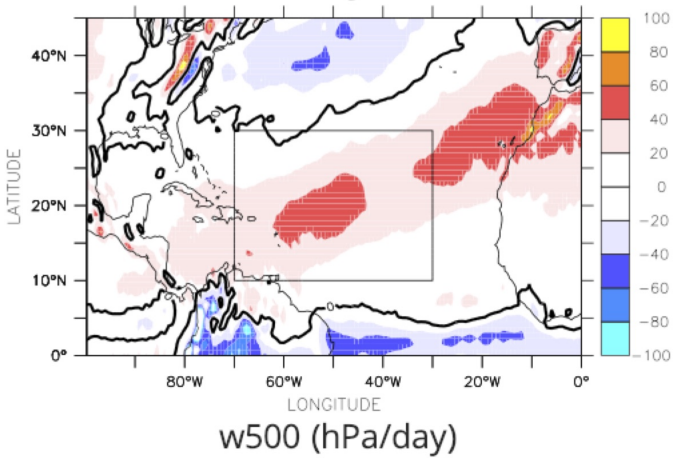

(c)

ERA-5 JFM 2012-2017

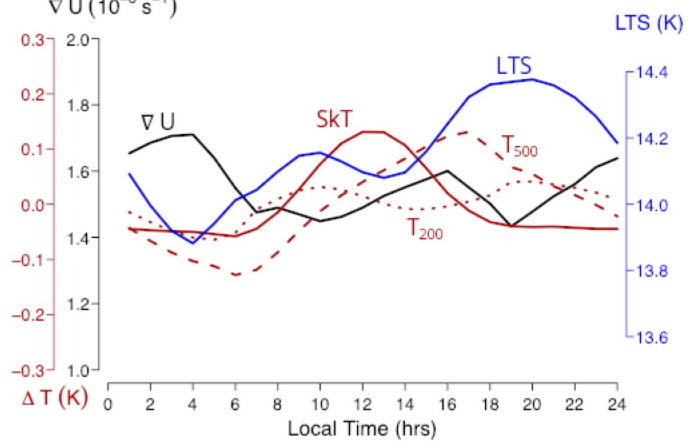

(b) ERA-Interim JAS 2012-2017

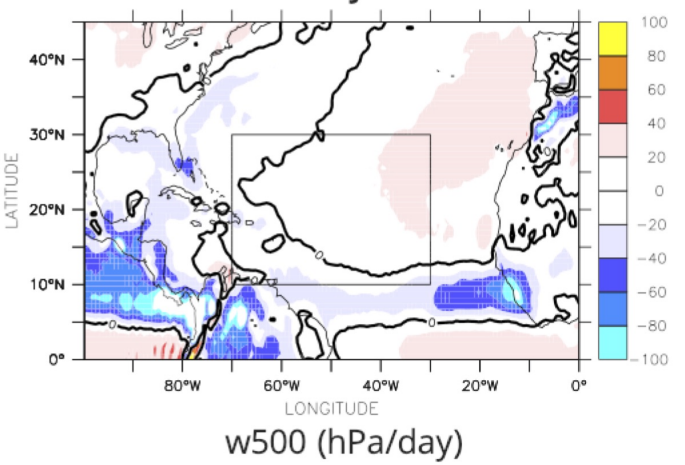

(d) ERA-5 JAS 2012-2017

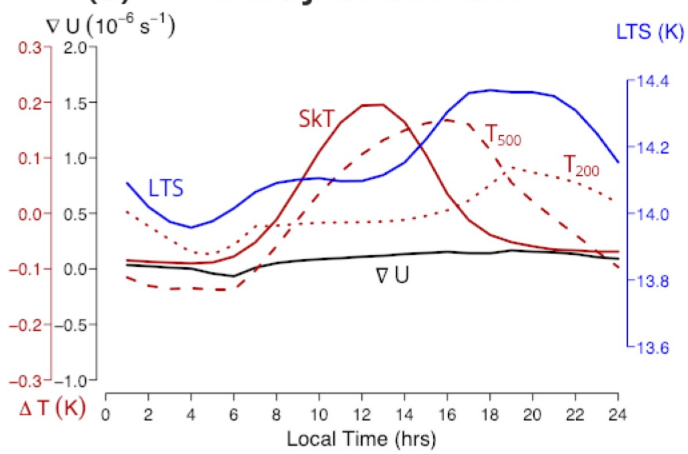

Figure 1. (top panel) Interannual averages of the $500 \mathrm{hPa}$ atmospheric vertical velocity (hPa/day) computed over the period 2012-2017 for (a) JFM and (b) JAS. The isoline indicates $\omega_{500}=0 \mathrm{hPa} /$ day. The box delineates the area of interest. (bottom panel) Composite diurnal cycles for (c) JFM and (d) JAS defined for the area of interest indicating: the average divergence for the $10-\mathrm{m}$ wind ( $\nabla U$ in $10^{-6} \mathrm{~s}^{-1}$; black curve), anomalies of SkT (in K; red curve), $T_{500}$ (in K; red-dashed curve) and $T_{200}$ (in K; red-dotted curve), and the average LTS (in K; blue curve). 
anomalies with respect to the mean daily states are shown by cloud types (Fig. $2 \mathrm{~b}$ and $\mathrm{f}$ ) and for RH (Fig. $2 \mathrm{c}$ and g). Figures 2 (d) and (h) present the daily variations of RH in situations filled with "Very Low" clouds exclusively.

Figures 2 (a) and (e) confirm that the VeryLow clouds are the dominant cloud type during JFM, followed by HighSemi clouds. The contributions of VeryLow, Low and HighSemi are more evenly prevalent during JAS. During both periods the frequency of occurrence of these cloud types indicate a strong diurnal cycle with a peak around 7:00 LT, and a dip early afternoon around 13:00 LT, as the solar heating inhibits the vertical development of clouds by stabilizing the column (Randall et al., 1991).

During both seasons, total cloud distribution for the VeryLow and Low classes (and to a lesser extent Medium) reaches a peak in the morning, between 0:00 LT and 8:00 LT caused by shallow convection (Fig. 2b-f). While VeryLow clouds display similar diurnal variations across both seasons, there are seasonal variations in the diurnal cycles of the other cloud types. The peak of the diurnal cycle for Low clouds shifts from 6:00-8:00 LT in JFM to 0:00-2:00 LT in JAS, and for HighOpaque and HighSemi clouds it shifts from the morning (4:00-11:00 LT) in JFM to the afternoon (12:00-20:00 LT) in JAS. The higher the clouds, the greater the shift in peak occurrence between JFM and JAS.

During the JAS period, HighOpaque cloudiness is maximal in the late afternoon and early night (16:00-24:00 LT). It coincides with a moistening of the upper troposphere (Fig. 2 b). This moistening may be induced by their detrainment of moisture (Soden \& Fu, 1995; Sassi et al., 2001; Garot et al., 2017) and by local lifting of moisture in regions of high cloud cover.

The diurnal variations of the tropospheric RH are shown in Fig 2 (c) and (g). The vertical profile displays diurnal vertical heterogeneity. The relative variations of $\mathrm{RH}$ within the ABL $(\sim 850-950 \mathrm{hPa})$ are of lower amplitude than in other layers. This is normal because the ocean surface maintains moist conditions in the ABL all day-long $(\sim 80 \%)$ and lessens moisture variations. In this layer, RH peaks around 6:00-8:00 LT when the cloud cover is maximal. Just above $(\sim 800-600 \mathrm{hPa}), \mathrm{RH}$ diurnal variations are maximal around 4:00 LT. A weak secondary moistening is visible around 20:00 LT in JFM. In the free troposphere $(\sim 600-300 \mathrm{hPa})$ this maximum point shifts to an earlier time (2:00-4:00 LT), and in both JFM and JAS, the maximum point is reached in the evening around 20:00 LT. Finally, in the upper layers (above $300 \mathrm{hPa}$ ) the first maximum point disappears and is replaced by a 


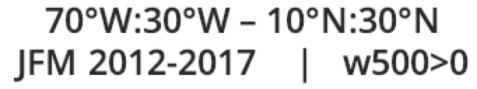

(a)
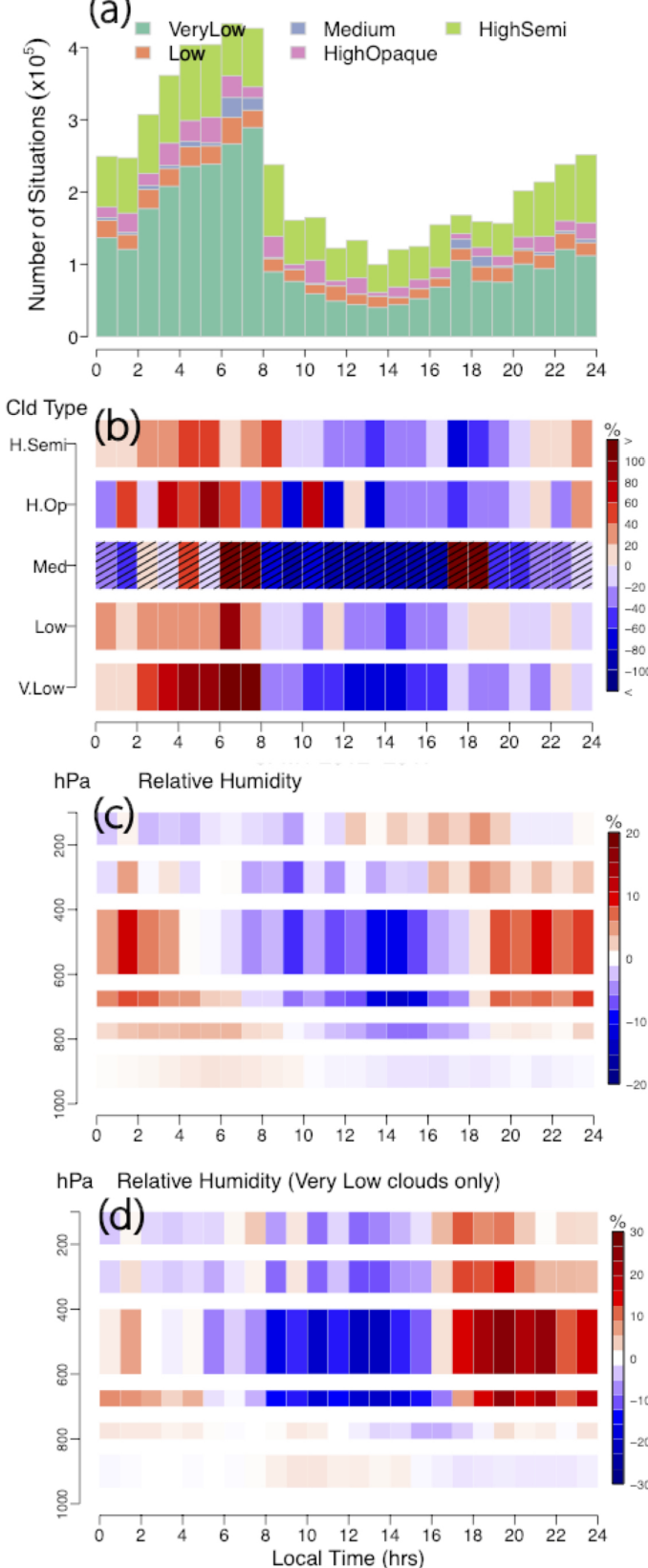

$70^{\circ} \mathrm{W}: 30^{\circ} \mathrm{W}-10^{\circ} \mathrm{N}: 30^{\circ} \mathrm{N}$ JAS 2012-2017 | w500>0
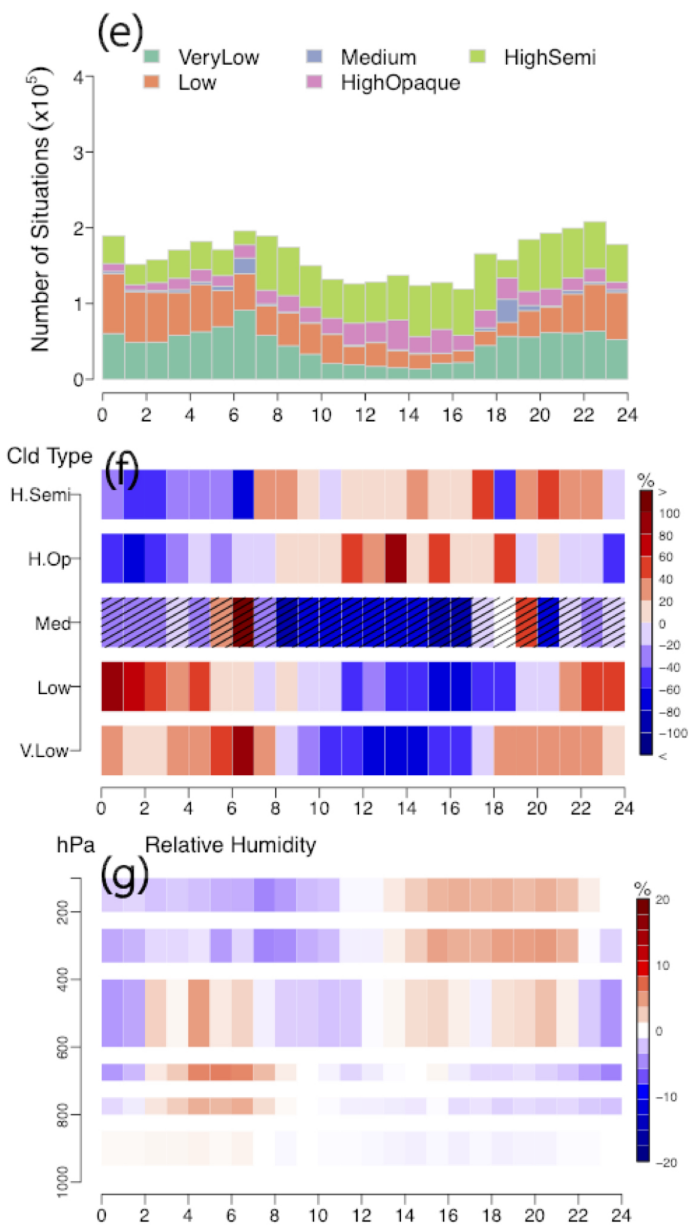

hPa Relative Humidity (Very Low clouds only)

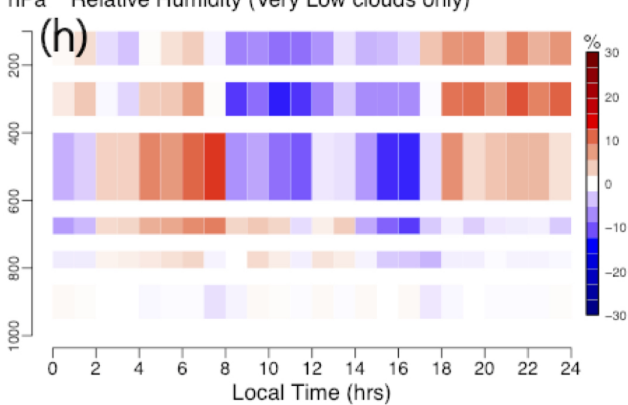

Figure 2. Composite diurnal cycles defined over the tropical Western Atlantic region during JFM (left column) and JAS (right column) over the period 2012-2017. Panels (a) and (e): prevalence of each cloud type accumulated for the area. Panels (b) and (f) : relative anomaly of cloud prevalence compared to their respective daily averages (in \%). The hatched part indicates that the computation is performed with less than $1 \%$ of the total population. Panels (c) and (g) : relative anomaly of the vertical profiles of $\mathrm{RH}$ relative to the daily average of the considered atmospheric layer (in \%). (d) and (h) same as (c-g) but using only the RH profiles associated with VeryLow clouds. 
strong drying while afternoon moistening is strengthened. These patterns are similar overall between the two seasons, but the diurnal gradients are weaker during JAS, when the region is on the edge of the ITCZ, compared to JFM, when the region is located within a strong large-scale subsidence. Fig 2 (c) and (g) reveal a vertical consistency across layers, with the moistening and drying shifting over time from the top layers to the bottom layers. It suggests that both the large-scale subsidence and diurnal pulses in the fluxes of atmospheric moisture have an influence.

The variability of $\mathrm{RH}$ in situations where only VeryLow clouds are detected in the SAPHIR pixels is presented in Fig 2 (d) and (h). Under these conditions, the vertical diurnal cycles of RH are more similar during JFM and JAS, with a strong daytime drying of the mid-troposphere (700 to $300 \mathrm{hPa}$ ) surrounded by moister atmospheric layers, and an early night moistening which becomes remarkably stronger after sunset (18:00-22:00 LT) during JFM. The JAS cycle is more pronounced in this case when compared to the cycle including all cloud types (Fig. $2(\mathrm{~g})$ ). This confirms that the vertical structure and diurnal variations of atmospheric moisture is strongly related with the diurnal cycle of clouds. The RH vertical diurnal cycle remains less pronounced during JAS than during JFM, which may be due to the lower frequency of prevalence of VeryLow clouds during JFM.

\subsection{Analysis of correlations}

To quantify the relationships between the moisture field and the clouds, Figure 3 displays lagged correlations between the harmonic fits on the $\mathrm{RH}$ profiles and the number of each cloud type. We also show the lag between the maxima as well as the lag between the minima defined from the fitted hourly evolutions. While the temperature is the firstorder driver of $\mathrm{RH}$, the other environmental parameters are also closely linked to $\mathrm{RH}$ at the diurnal scale. These statistics reveal that the co-variations between the different cloud categories and RH the low troposphere on one hand, and RH in the free troposphere on the other hand, have notable opposite variations during JFM. This is less obvious for JAS.

\subsubsection{Winter patterns}

During JFM, RH diurnal variations display similar departures with respect to the VeryLow and Low diurnal variations. Below $750 \mathrm{hPa}$, the diurnal variations of $\mathrm{RH}$ are highly 

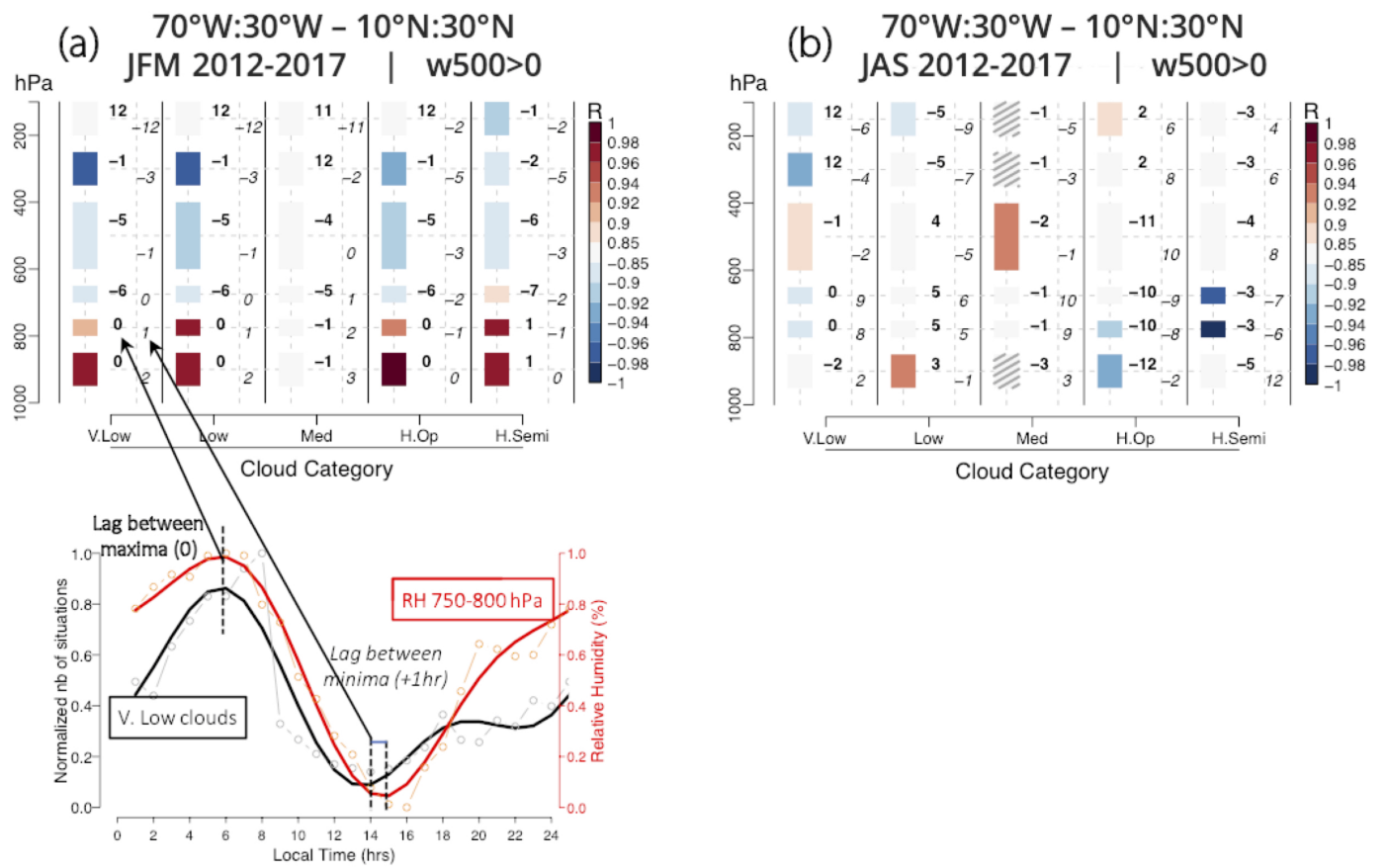

Figure 3. Lagged correlation (intensity in color scale) computed for the subsiding regime category between $\mathrm{RH}$ at a given pressure level and the cloud prevalence sorted by category. January-February-March (JFM) and (b) July-August-September (JAS). As described by the inset below, the bold number is the lag between the maximum of the two times series and the italic number is the lag between their minimum. If the lag is $<0$ then the maximum/minimum of the chosen cloud prevalence precedes the maximum/minimum of RH. Dashed boxes are non-significant correlations with p.values $>0.05$. 
correlated with those of the VeryLow $\left(\mathrm{R}_{V \cdot \text { Low }}=0.90-0.96\right)$ and Low $\left(\mathrm{R}_{\text {Low }}=0.97\right)$ cloud categories. Such correlations suggest that common processes link both diurnal cycles in the PBL. The clouds and RH maxima coincide (lag $=0)$ while the RH diurnal minima are slightly shifted with respect to the cloud minima ( 1 to 2 hours). This delay is consistent with Fig. 2 (b) and (c) and indicates that the moistening of the layer may result from the dilution of low-level clouds as suggested by (Eastman \& Warren, 2014). Note that it coincides with the daytime increase of $T_{500}$ (Fig. 1c), so the drying processes of this part of the atmosphere are in phase with the warming of the free troposphere. This suggests that the daytime warming of the mid-troposphere, through shortwave (near-infrared) absorption by clouds and water vapor, as well as by the surface heating, is strongly linked to the dilution of low-level clouds and the subsequent moistening of the near-surface troposphere.

In the mid-troposphere $(\sim 700-400 \mathrm{hPa})$ correlation magnitudes remain high but become negative $\left(\mathrm{R}_{V . L o w}=-0.88, \mathrm{R}_{\text {Low }}=-0.90\right)$, with little to no lag between minima, while $\mathrm{RH}$ peaks 5-6hrs earlier than the clouds. It suggests that processes different than those in the PBL jointly affect the diurnal cycles of $\mathrm{RH}$ and clouds. Moving to the upper troposphere, the RH diurnal minima increasing lead the cloud diurnal minima (e.g. $-3 \mathrm{hrs}$ at $250-350 \mathrm{hPa}$ ), while the lead of RH diurnal maxima gradually decreases (e.g. from $-5 \mathrm{hrs}$ at $400-600 \mathrm{hPa}$ to $-1 \mathrm{hr}$ at $250-350 \mathrm{hPa}$ ), indicating that the processes at play are vertically connected.

The correlations and lags profiles of the RH diurnal variations display similar features with HighOpaque and HighSemi clouds. As for VeryLow and Low clouds, in the PBL the correlations are high and positive while somewhat lower and negative in the mid-troposphere. The $\mathrm{RH}$ diurnal minima increasing lead the cloud diurnal minima from the surface (lag $=0 \mathrm{hr}$ ) to $250-350 \mathrm{hPa}$ (lag=-5hrs) except at the highest altitude range (lag=-2hrs). The RH maxima display slight or no delay in the PBL, and significant leading time just above the PBL (lag $\sim-6 \mathrm{hrs})$ that decreases with altitude. As noted in Fig 2 (c) and (g), the moistening and drying shifts over time from the top layers to the bottom layers suggest the influence of large-scale subsidence and diurnal pulses in the fluxes of atmospheric moisture.

It is hypothesized that the warming of the mid-troposphere by shortwave absorption triggers air masses to lift a few hours later from increased buoyancy produced by heating (Ackerman et al., 1988; Mather et al., 2007; Powell et al., 2012). This lifting causes the midtroposphere to dry while supplying the upper tropospheric layer with additional moisture. This moisture is later pumped to maintain HighSemi clouds that could develop from the debris of dissipating HighOpaque clouds (i.e. anvils) (Luo \& Rossow, 2004). Such physical 
links could be evaluated in hourly reanalyses such as ERA5, by looking at the similarities in the diurnal cycles of clouds and RH and at the evolution of the 3-D wind field and heating profiles. The use of field campaigns data (e.g. the recent EUREC4A campaign; Bony et al. (2017)) would also be greatly beneficial.

\subsubsection{Summer patterns}

During JAS, large-scale ascent associated with the ITCZ influences the cloud processes in the region. The observed diurnal moisture and clouds variabilities are more strongly associated with the diurnal pulses of the ITCZ than during JFM. The higher diversity of cloud types in JFM (Fig. 2e) makes it more difficult to analyze how a specific cloud type affects the RH diurnal cycle. It is reflected by the lower correlations between $\mathrm{RH}$ diurnal variations and those of clouds than during JFM. For example, the correlations with the Medium cloud category is weak or non-significant.

The profiles of correlation and lags display less structure than during JFM, but one can note specific patterns. First, the lags between the maxima of $\mathrm{RH}$ and clouds prevalence change their sign near $400 \mathrm{hPa}$ for all clouds categories but HighSemi. This suggests that different moistening processes occur below and above 400hPa. In situations of HighSemi cloud cover the entire troposphere moistens 3 to $5 \mathrm{hrs}$ after the cloud maximum growth. Second, the lags between the minima change their sign near $700 \mathrm{hPa}$ for all cloud categories without exception. Hence, a drying below $700 \mathrm{hPa}$ precedes the minimum of formation for the VeryLow and Low clouds while above this is the opposite (minimum of clouds before minimum of RH). For the HighOpaque and HighSemi clouds, the processes at play turn the diurnal cycles: below $700 \mathrm{hPa}$ the minimum of $\mathrm{RH}$ follows the minimum of prevalence of these clouds ( 6 to 9 hrs after) while above the drying precede their dissipation by 4 to $10 \mathrm{hrs}$.

We believe that these results corroborate studies on the diurnal variabilities of convection and precipitation that highlight radiative-dynamics-convective interplays (Randall et al., 1991). These studies suggest that large anvil clouds dampen the heating of the atmospheric column (via their shade). It feedbacks on precipitation via locally-enhanced upward motion within the cloudy column as compared to neighboring cloud-free columns (Chen \& Houze, 1997; Ruppert \& Klocke, 2019). 
The moistening patterns of the upper troposphere observed during the JFM period point towards different mechanisms. Overall the presence of upper level cloudiness is significantly reduced. Peak occurrence (albeit small) is observed near sunrise while there is an upper level moistening between 14:00 and 22:00 LT. This local moistening is more pronounced when no elevated clouds are present in the column (Fig. 2 (d)). It could be induced by horizontal advection of moisture from remote areas (Pierrehumbert \& Roca, 1998; Sherwood et al., 2010), and could be associated to the diurnal pulses of the ITCZ (Ciesielski et al., 2018) as well as by variations in the upward motion forced by solar heating.

\section{Summary and conclusions}

In this study, we show how the Megha-Tropiques satellite adds value to the study of the diurnal cycle of atmospheric moisture. By collocating SAPHIR observations with those of cloud types and environmental conditions over the Western Atlantic Trades during JFM and JAS 2012-2017, a robust depiction of the diurnal co-evolution of clouds and moisture in areas remotely connected to the rainy ITCZ is provided.

Here, we target the diurnal variation of RH in areas less affected by strong convective motions and dominated by a mean downward flow. Fig. 4 provides a sketch that summarizes the observed patterns.

In the strongly subsiding situation $\left(\omega_{500}>>0\right.$, corresponding to JFM) :

(i) After sunrise (06:00-12:00 LT), the mid-troposphere is mostly free of clouds and undergoes a strong drying linked to the mean downward motion that brings dry air masses from the colder upper troposphere.

(ii) The daytime warming (12:00-18:00 LT) of the mid-troposphere is linked to the dilution of low-level clouds and triggers moistening of the low troposphere a few hours later.

(iii) At sunset (18:00-24:00 LT), the longwave radiative cooling starts to dominate, thereby increasing the vertical cooling rate. The increased temperature gradient yields mixing moisture vertically. We hypothesize that this behavior is remotely connected to the ITCZ diurnal pulses and its afternoon peak, as suggested by (Ruppert \& Klocke, 2019).

(iv) The lifting of moist air in the upper troposphere triggers the formation of high-altitude cirriform clouds at night (18:00-24:00 LT). Moisture is pumped from below to maintain them. 

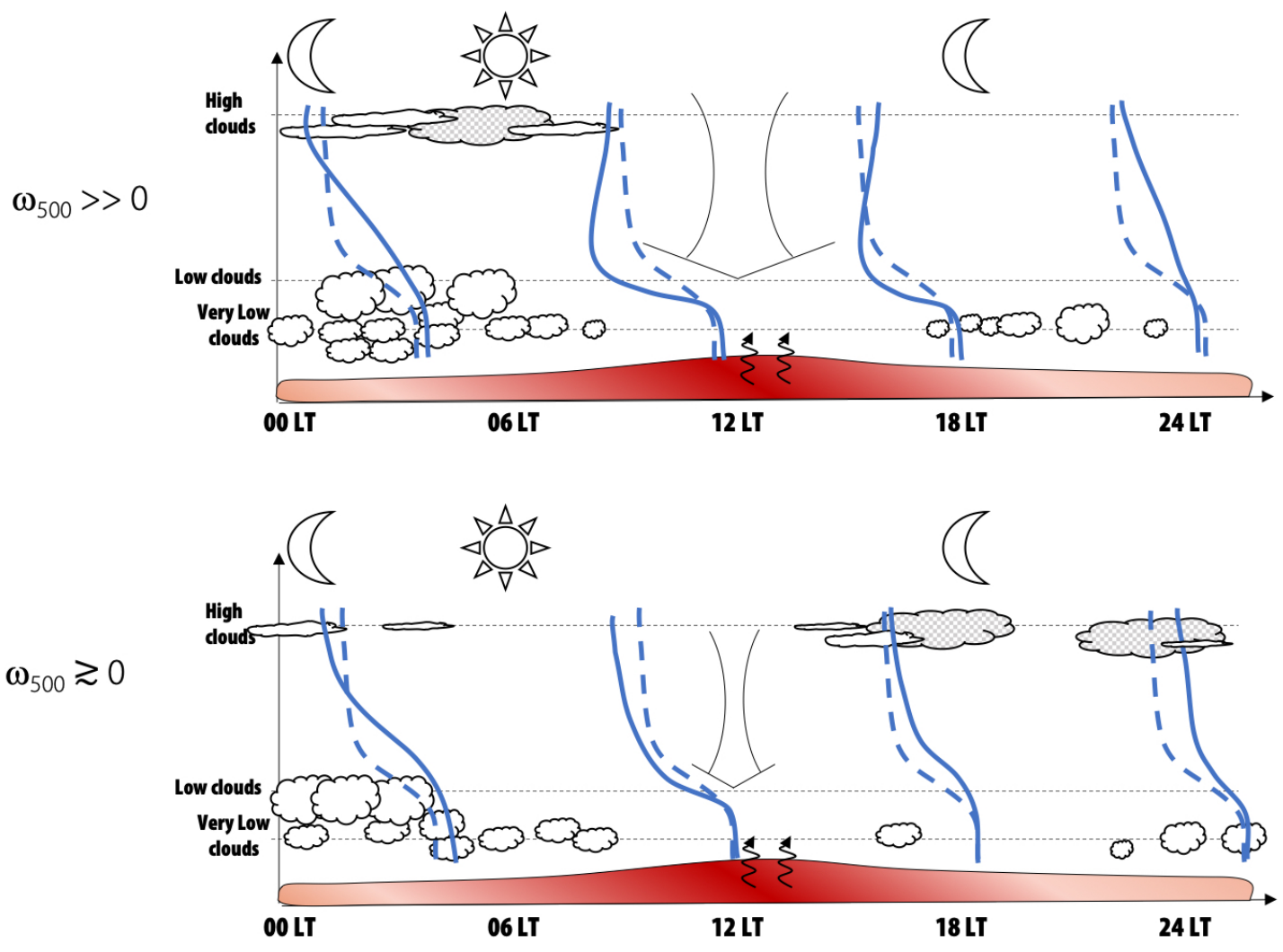

Figure 4. Diagram that shows the evolution of the RH profile (solid line) around its daily average (dashed line). The top panel is for the period of strong subsidence (i.e. JFM, $\omega_{500}>>0$ ) and the bottom panel is for the period of moderate subsidence (i.e. JAS, $\omega_{500} \simeq 0$ ). HighOpaque clouds are in gray while HighSemi clouds are in white, and the large vertical arrows represent the mean downward motions. 
In the moderate subsiding situation $\left(\omega_{500} \simeq 0\right.$, corresponding to JAS) :

(i) The presence of high-altitude clouds during daytime (12:00-18:00 LT) shields the atmospheric column from solar forcing and reduces the drying due to large-scale subsidence.

(ii) The development of upper tropospheric opaque clouds after sunset (18:00-06:00 LT), associated with the ITCZ convective systems, constitutes a local source of moisture via detrainment.

It is hypothesized that the development of VeryLow and Low clouds is driven by conditions independent of the season, whilst the other categories of clouds are driven by large scale dynamics conditioned by the seasonal variations of the ITCZ.

These findings help to refine an atmospheric moisture budget for a quiescent area of the tropics, and emphasize the important role of relative humidity constrained by clouds and dynamics. In future works the impact of the seasonal and diurnal variability of the ITCZ will be considered thanks to this observational dataset. The impact of these connections will be explored by taking the entire tropical belt into consideration, and by looking at moisture profiles dependent on cloud types. This undertaking will contribute to improve the assessment of the cloud-water vapor feedback.

\section{Acknowledgments}

H. B. acknowledges CNES for its financial support for the scientific activities within the Megha-Tropiques project. P.-E. K. acknowledges funding through the Labex IPSL program. We also thank J. Ruppert for fruitful exchanges on the diurnal feedbacks and Mary Minnock for her English revision. We also thank the reviewers for their suggestions and comments that helped to improve the manuscript. The support of S. Bouffiès-Cloché on ERA5 data is greatly appreciated, as is that of the IPSL/ESPRI for providing computing resources. We also thank the national Aeris data center that hosts the entire Megha-Tropiques data archive. All data used are freely available from the Aeris portal https://en.aeris-data.fr.

\section{References}

Ackerman, T., Liou, K.-N., Valero, F., \& Pfister, L. (1988). Heating rates in tropical anvils. J. Atmos. Sci., 45(10), 1606-1623, doi:10.1175/15200469(1988)045;1606:HRITA ¿2.0.CO;2.

Bellenger, H., Takayabu, Y. N., T., U., \& K., Y. (2010). Role of diurnal warm layers in 
the diurnal cycle of convection over the tropical Indian Ocean during MISMO. Mon. Wea. Rev., 138, 2426-2433, doi:10.1175/2010MWR3249.1.

Bony, S., Stevens, B., Ament, F., Bigorre, S., Chazette, P., Crewell, S., .. W Wirth, M. (2017). EUREC4A: a field campaign to elucidate the Couplings between clouds, convection and circulation. Surv. Geophys, 38, 1529-1568, doi:10.1007/s10712-017-9428-0.

Bony, S., Stevens, B., Frierson, D. M., Jakob, C., Kageyama, M., Pincus, R., ... Webb, M. J. (2015). Clouds, circulation and climate sensitivity. Nature Geosci., 8, 261-268, doi:10.1038/ngeo2398.

Brogniez, H., Fallourd, R., Mallet, C., Sivira, S., \& Dufour, C. (2016). Estimating confidence intervals around relative humidity profiles from satellite observations: application to the SAPHIR sounder. J. Atmos. Oceanic Technol., 33, 1005-1022, doi:10.1175/JTECH-D-15-0237.1.

Brogniez, H., Kirstetter, P.-E., \& Eymard, L. (2013). Expected improvements in the atmospheric humidity profile retrieval using the Megha-Tropiques microwave payload. Q. J. R. Meteorol. Soc., 139, 842-851, doi:10.1002/qj.1869.

Burns, B., Wu, X., \& Diak, G. (1997). Effects of precipitation and cloud ice on brightness temperatures in AMSU moisture channels. IEEE Trans. Geosci. Remote Sens., 35, 1429-1437.

Chen, S., \& Houze, R. (1997). Diurnal variation and life-cycle of deep convective systems over the tropical Pacific warm pool. Q. J. R. Meteorol. Soc., 123, 357-388, doi:10.1002/qj.49712353806.

Chepfer, H., Brogniez, H., \& Noel, V. (2019). Diurnal variations of cloud and relative humidity profiles across the tropics. Nature Sci. Rep., 9, 16045, doi:10.1038/s41598019-52437-6.

Chung, E.-S., Soden, B., Sohn, B.-J., \& Schmetz, J. (2013). An assessment of the diurnal variation of upper tropospheric humidity in reanalysis data sets. J. Geophys. Res., 118, 3425-3430, doi:10.1002/jgrd.50345.

Chung, E.-S., Sohn, B.-J., Schmetz, J., \& Koenig, M. (2007). Diurnal variation of upper tropospheric humidity and its relations to convective activities over tropical Africa. Atmos. Chems. Phys., 7, 351-381.

Ciesielski, P., Johnson, R., Schubert, W., \& Ruppert, J. (2018). Diurnal cycle of the ITCZ in DYNAMO. J. Clim., 31, 4543-4562, doi: 10.1175/JCLI-D-17-0670.1.

Derrien, M., \& Le Gléau, H. (2005). MSG/SEVIRI cloud mask and type from SAFNWC. 
Int. J. Remote Sens., 26(21), 4707-4732, doi:10.1080/01431160500166128.

Eastman, R., \& Warren, S. G. (2014). Diurnal cycles of Cumulus, Cumulonimbus, Stratus, Stratocumulus, and Fog from surface observations over land and ocean. J. Clim., 27, 2386-2404, doi:10.1175/JCLI-D-13-00352.1.

Garot, T., Brogniez, H., Fallourd, R., \& Viltard, N. (2017). Evolution of the distribution of upper tropospheric humidity over the Indian Ocean: connection with largescale advection and local cloudiness. J. Appl. Meteor. Climatol., 56, 2035-2052, doi: 10.1175/JAMC-D-16-0193.1.

Hartmann, D., Hendon, H., \& Houze, R. (1984). Some implications of the mesoscale circulation in tropical cloud clusters for large-scale dynamics and climate. J. Atmos. Sci., 41(1), 113-121, doi:10.1175/1520-0469(1984)041¡0113:SIOTMC¿2.0.CO;2.

Hoffmann, L., Gunther, G., Li, D., Stein, O., Wu, X., Griessbach, S., .. Wright, J. (2019). From ERA-Interim to ERA5: considerable impact of ECMWF's next generation reanalysis on Lagrangian transport simulations. Atmos. Chem. Phys., 19, 3097-3124, doi: 10.5194/acp-19-3097-2019.

Klein, S., \& Hartmann, D. (1993). The seasonal cycle of low stratiform clouds. J. Clim., $6,1587-1606$

Klein, S., Hartmann, D., \& Norris, J. (1995). On the relationships among low-cloud structure, sea surface temperature and atmospheric circulation in the summertime Northeast Pacific. J. Clim., 8, 1140-1155.

Konsta, D., Chepfer, H., \& Dufresne, J.-L. (2012). A process oriented characterization of tropical oceanic clouds for climate model evaluation, based on a statistical analysis of daytime A-train observations. Clim. Dyn., 39, 2091-2108, doi:10.1007/s00382-0121533-7.

Luo, Z., \& Rossow, W. (2004). Characterizing tropical cirrus life cycle, evolution and interaction with upper-tropospheric water vapor using Lagrangian trajectory analysis of satellite observations. J. Clim., 17, 4541-4563, doi:10.1175/3222.1.

Mapes, B. E., \& Houze, R. A. (1993). Cloud clusters and superclusters over the oceanic warm pool. Mon. Wea. Rev., 121, 1398-1415.

Mather, J., McFarlane, S., Miller, M., \& Johnson, K. (2007). Cloud properties and associated radiative heating rates in the tropical western Pacific. J. Geophys. Res., 112(D05201), doi:10.1029/2006JD007555.

Moradi, I., Arkin, P., Ferraro, R., Eriksson, P., \& Fetzer, E. (2016). Diurnal variation of 
tropospheric relative humidity in tropical regions. Atmos. Chem. Phys., 16, 6913-6929, doi:10.5194/acp-16-6913-2016.

Nitta, T., \& Esbensen, S. (1974). Diurnal variations in the Western Atlantic Trades during the BOMEX. J. Roy. Meteorol. Japan, 52(2), 254-257.

Noel, V., Chepfer, H., Chiriaco, M., \& Yorks, J. (2018). The diurnal cycle of cloud profiles over land and ocean between $51^{\circ} \mathrm{S}$ and $51^{\circ} \mathrm{N}$, seen by the CATS spaceborne lidar from the International Space Station. Atmos. Chem. Phys., 9457-9473, doi:10.5194/acp-189457-2018.

Pierrehumbert, R., \& Roca, R. (1998). Evidence for control of Atlantic subtropical humidity by large-scale advection. Geophys. Res. Lett., 25, 4537-4540.

Powell, S., Houze, R., Kumar, A., \& McFarlane, S. (2012). Comparison of simulated and observed continental tropical anvil clouds and their radiative heating profiles. $J$. Atmos. Sci., 69, 2662-2681, doi:10.1175/JAS-D-11-0251.1.

Randall, D., Harshvardhan, \& Dazlich, D. (1991). Diurnal variability of the hydrologic cycle in a general circulation model. J. Atmos. Sci., 48(1), 40-62.

Riehl, H. (1954). Tropical meteorology. McGraw Hill, New York.

Roca, R., Brogniez, H., Chambon, P., Chomette, O., Cloché, S., Gosset, M., ... Viltard, N. (2015). The Megha-Tropiques Mission: a review after three years in orbit. Front. Earth Sci., 3, doi:10.3389/feart.2015.00017.

Rozendaal, M., Leovy, C., \& Klein, S. (1995). An observational study of diurnal variations of marine stratiform clouds. J. Clim., 8, 1795-1809.

Ruppert, J. H. (2016). Diurnal timescale feedbacks in the tropical cumulus regime. J. Adv. Model. Earth. Syst., 8, 1483-1500, doi:10.1002/2016MS000713.

Ruppert, J. H., \& Johnson, R. H. (2015). Diurnally modulated cumulus moistening in the preonset stage of the Madden-Julian oscillation during DYNAMO. J. Atmos. Sci., 72, 1622-1647, doi:10.1175/JAS-D-14-0218.1.

Ruppert, J. H., \& Klocke, D. (2019). The two diurnal modes of tropical upward motion. Geophys. Res. Lett., 46, doi:10.1029/2018GL081806.

Sakaeda, N., Powell, S. W., Dias, J., \& Kiladis, G. N. (2018). The diurnal variability of precipitating cloud populations during DYNAMO. J. Atmos. Sci., 75, 1307-1326, doi:10.1175/JAS-D-17-0312.1.

Sakazaki, T., Hamilton, K., Zhang, C., \& Wang, Y. (2017). Is there a stratospheric pacemaker controlling the daily cycle of tropical rainfall ? Geophys. Res. Lett., 44, 1998- 
2006, doi:10.1002/2017GL072549.

Sassi, F., Salby, M., \& Read, W. (2001). Relationship between upper tropospheric humidity and deep convection. J. Geophys. Res., 106(D15), 17,133-17,146.

Sèze, G., Pelon, J., Derrien, M., Le Gléau, H., \& Six, B. (2015). Evaluation against CALIPSO lidar observations of the multi-geostationnary cloud cover and type dataset assembled in the framework of the Megha-Tropiques mission. Quart. J. Roy. Meteor. Soc., 141 (688), 774-797, doi:10.1002/qj.2392.

Sherwood, S., Roca, R., Weckwerth, T., \& Andronova, N. (2010). Tropospheric water vapor, convection and climate. Rev. Geophys., 48, doi:10.1029/2009RG000301.

Sivira, R., Brogniez, H., Mallet, C., \& Oussar, Y. (2015). A layer-averaged relative humidity profile retrieval for microwave observations: design and results for the MeghaTropiques payload. Atmos. Meas. Tech, 8, 1055-1071.

Soden, B., \& Fu, R. (1995). A satellite analysis of deep convection, upper-tropospheric humidity and the greenhouse effect. J. Clim., 8, 2333-2351.

Stephens, G., Vane, D., Boain, R., Mace, G., Sassen, K., Wand, Z., ... the CloudSat science team (2002). The CloudSat mission and the A-Train: a new dimension of space-based observations of clouds and precipitation. Bull. Am. Meteor. Soc., 83, 1771-1790, doi 10.1175/BAMS-83-12-1771.

Vial, J., Vogel, R., Bony, S., Stevens, B., Winker, D., Cai, X., .. Brogniez, H. (2019). A new look at the daily cycle of tradewind cumuli. J. Adv. Model. Earth. Syst., 11, 3148-3166, doi:10.1029/2019MS001746.

Wood, R. (2012). Stratocumulus clouds. Mon. Wea. Rev., 140, 2373-2423, doi:10.1175/MWR-D-11-00121.1.

Woolnough, S., Slingo, J., \& Hoskins, B. (2004). The diurnal cycle of convection and atmospheric tides in an aquaplanet GCM. J. Atmos. Sci., 61, 2559-2573.

Yang, G.-Y., \& Slingo, J. (2001). The diurnal cycle in the tropics. Mon. Wea. Rev., 129, 784-801. 